\title{
The degradation of reactive red dye from wastewaters by advanced electrochemical oxidation
}

\author{
S. Moţoc, F. Manea, A. Pop, A. Baciu, G. Burtică \& R. Pode \\ "Politehnica" University of Timisoara, Timisoara, Romania
}

\begin{abstract}
In the present study, electrochemical degradation experiments were conducted to degrade a textile dye namely Reactive Red 147 (RR) from water. The process performance was assessed in terms of the electrochemical decolourisation and mineralization of aqueous RR solutions. Electrolyses were carried out under galvanostatic conditions using boron-doped diamond (BDD) electrodes in $0.1 \mathrm{M}$ $\mathrm{Na}_{2} \mathrm{SO}_{4}$ supporting electrolyte using undivided electrolytic cell. Also, the effect of in-situ electrolytic generation of chlorine/hypochlorite at BDD electrode from a mixture of $0.05 \mathrm{M} \mathrm{Na}_{2} \mathrm{SO}_{4}$ and $0.05 \mathrm{M} \mathrm{NaCl}$ supporting electrolyte on the electrochemical degradation process of RR has been studied. Prior to electrolysis application, the electrochemical behaviour of RR dye on BDD electrode was characterized in both supporting electrolytes without/with chloride presence by cyclic voltammetry in order to establish the working potential-current conditions. The influence of operating variables on the electrochemical process efficiency was studied as a function of the supporting electrolyte type, current density, and the initial $\mathrm{pH}$. Under all applied conditions, the complete decolourisation of dye synthetic solution was achieved after several minutes of electrolysis. Acidic medium and the chlorine/hypochlorite generation favored the decolorization and mineralization process of RR. The complete mineralization of dye synthetic solution was not achieved, and the maximum mineralization efficiency of $35 \%$ was reached under the working conditions of hypochlorite presence, which informs about the intermediates generation during the application of electrochemical process based on BDD electrodes.

Keywords: advanced wastewater treatment, electrochemical degradation, Reactive Red 147 dye, boron-doped diamond electrode.
\end{abstract}




\section{Introduction}

The rapid increase in population and increased demand for industrial systems to meet human necessities have created problems such as overexploitation of available resources, leading to pollution of land, air and water surroundings.

With the increased demand for textile products, the wastewater of textile industry is increasing proportionally, making it one of the main sources of worldwide severe pollution problems. In particular, the release of textile wastewater to the natural water courses is the main dispersion path of a wide variety of dyestuff in the environment [1].

Many dyes and their breakdown products are toxic and/or mutagenic to aquatic life. Azo dyes are among the most widely used synthetic dyes and usually considered as major pollutants in textile wastewater [2].

At the moment, several biological, physical and chemical processes are used to treat dye effluents [2-6]. However, conventional sewage plant treatments are usually ineffective for dye removal because of their high biochemical stability, their relatively high molecular weight and the presence of aromatic rings.

In recent years, there has been an increasing interest in the use of electrochemical methods for the destruction of toxic and biorefractory organic pollutants.

These methods use the electron as the main reagent, but also require the presence of supporting electrolytes. In general, the supporting electrolytes exist in the dye-containing wastewaters to be treated, but not always in sufficient concentrations. These processes can operate at ambient temperature without a need of temperature control $[2,7]$.

It is well-known that the electrode material is the most important parameter in the electrochemical oxidation of organics, constituting the key for process performance. Boron-doped diamond (BDD) electrode exhibits a great potential for electrochemical applications, especially for the treatment of wastewater and drinking water because of the extraordinary chemical inertness offering the opportunity to use such electrodes (anodes as well as cathodes) in very aggressive media [8-10].

The aim of the work is to assess the performance of boron-doped diamond (BDD) electrodes in $0.05 \mathrm{M} \mathrm{Na}_{2} \mathrm{SO}_{4}$ and $0.05 \mathrm{M} \mathrm{NaCl}$ supporting electrolyte for Reactive Red 147 (RR) dye electrooxidation based on the electrochemical decolourisation and mineralization degrees. The electrochemical behaviour of RR dye on BDD electrode was studied cyclic voltametry (CV) technique to select the operating variables in relation with the current density. The effect of the current density and $\mathrm{pH}$ was studied to determine the optimum working conditions for bulk electrolysis under galvanostatic regime.

\section{Experimental}

\subsection{Electrochemical characterization of BDD electrode}

The electrochemical behaviour of the disc BDD electrode with the surface areas of $0.07068 \mathrm{~cm}^{2}$ (Windsor Scientific Ltd, UK) in the presence of RR dye was 
studied by cyclic voltammetry (CV). Subsequently, an electrochemical pretreatment by three repetitive cycling between $-0.5 \mathrm{~V}$ to $2 \mathrm{~V}$ vs. SCE in $0.1 \mathrm{M}$ $\mathrm{Na}_{2} \mathrm{SO}_{4}$, and $0.05 \mathrm{M} \mathrm{Na}_{2} \mathrm{SO}_{4}$ and $0.05 \mathrm{M} \mathrm{NaCl}$ supporting electrolytes was performed. All measurements were carried out using an Autolab potentiostat/galvanostat PGSTAT 302 (Eco Chemie, The Netherlands) controlled with GPES 4.9 software and a three-electrode cell, with a saturated calomel electrode as reference electrode, a platinum counter electrode and BDD working electrode.

\subsection{Bulk electrolysis experiments and analytical procedures}

The electrochemical experiments were carried out at room temperature $\left(22-25^{\circ} \mathrm{C}\right)$ by batch process using an undivided cell of $0.7 \mathrm{dm}^{3}$ volume in $0.05 \mathrm{M}$ $\mathrm{Na}_{2} \mathrm{SO}_{4}$ and $0.05 \mathrm{M} \mathrm{NaCl}$ supporting electrolyte. The solution $\mathrm{pH}$ was initially adjusted to 3 and 5 with small volumes of $\mathrm{H}_{2} \mathrm{SO}_{4}$, and respectively to 9 with $\mathrm{NaOH}$ solution. The BDD/Nb electrodes $(100 \mathrm{~mm} \times 50 \mathrm{~mm} \times 1 \mathrm{~mm})$ with $280 \mathrm{~cm}^{3}$ geometric area provided by CONDIAS, Germany were used as anodes, and stainless steel plates (100 $\mathrm{mm}$ x $50 \mathrm{~mm} \times 1 \mathrm{~mm})$ were employed as cathodes under vertical arrangement. A regulated DC power supply (HY3003, MASTECH) was used under galvanostatic regime at current densities of 10 and $30 \mathrm{~mA} \mathrm{~cm}^{-2}$.

After each minute, samples were drawn from the cell and RR dye degradation was followed by UV-VIS spectroscopy using a Varian Cary UV-VIS spectrophotometer. RR mineralization was checked by TOC parameter which was analyzed using a Shimadzu TOC analyzer. An Inolab WTW pH meter was used to measure the solution $\mathrm{pH}$. General parameters for the assessment of the performance of the applied processes were used.

Thus, the decolourisation of RR dye was followed based on absorbance recorded at $525 \mathrm{~nm}\left(\mathrm{~A}_{525}\right)$. The percentage of colour removal was determined using the expression (1):

$$
\text { Colour removal }(\%)=\frac{\left(A_{525,0}-A_{525}\right)}{A_{525,0}} \times 100 \quad(\%)
$$

The electrochemical efficiency for RR dye oxidation was determined based on eqn. (2):

$$
E_{D B R}=\frac{\left(R R_{0}-R R\right)}{Q * S} \times V\left(\mathrm{mgC} \cdot \mathrm{cm}^{-2}\right)
$$

where $R_{0}-R R$ represent the change in the $R R$ dye concentration determined by $\mathrm{A}_{525}$, during experiments for a charge consumption of $\mathrm{Q}$ corresponding to various electrolysis time, $\mathrm{V}$ is the sample volume $\left(700 \mathrm{~cm}^{3}\right)$ and $\mathrm{S}$ is the area of the electrode surface $\left(\mathrm{cm}^{2}\right)$.

The electrochemical efficiency for RR dye mineralization defined as an overall efficiency for complete oxidation to $\mathrm{CO}_{2}$ was determined based on 
eqn. (2) modified as (2') taking into consideration the change in TOC measurements during experiments, determining $\left(\mathrm{TOC}_{0}-\mathrm{TOC}\right)$ :

$$
E_{T O C}=\frac{\left(T O C_{0}-T O C\right)}{Q * S} \times V
$$

The mineralization current efficiency (MCE, \%), defined also as current output for direct faradayc complete oxidation, for each electrolyzed solution was calculated based on eqn. (3):

$$
M C E=\frac{n F V_{s} \Delta(T O C)_{\exp }}{4.32 \times 10^{7} \mathrm{mIt}} \times 100
$$

where $\mathrm{n}$ is the number of electrons consumed in the mineralization process of RR dye, $\mathrm{F}$ is the Faraday constant $\left(=96487 \mathrm{C} \mathrm{mol}^{-1}\right), \mathrm{V}_{\mathrm{s}}$ is the solution volume $\left(\mathrm{dm}^{3}\right), \Delta(\text { TOC })_{\exp }$ is the experimental TOC decay $\left(\mathrm{mg} \mathrm{dm}^{-3}\right), 4.32 \times 10^{7}$ is a conversion factor for units homogenization $\left(=3600 \mathrm{~s} \mathrm{~h}^{-1} \times 12000 \mathrm{mg}\right.$ of carbon $\left.\mathrm{mol}^{-1}\right), \mathrm{m}$ is the number of carbon atoms in RR dye, I is the applied current (A), and $t$ is time (h). The number of electrons consumed is determined based on the overall mineralization reaction of RR dye to $\mathrm{CO}_{2}\left(\mathrm{C}_{31} \mathrm{H}_{14} \mathrm{~N}_{6} \mathrm{~S}_{4} \mathrm{O}_{14} \mathrm{Na}_{14} \mathrm{~F} 2 \mathrm{Cl}+\right.$ $33 \mathrm{H}_{2} \mathrm{O}+33 \mathrm{HOCl} \rightarrow 31 \mathrm{CO}_{2}+14 \mathrm{Na}^{+}+2 \mathrm{~F}^{-}+34 \mathrm{Cl}^{-}+4 \mathrm{SO}_{4}{ }^{2-}+6 \mathrm{NH}_{4}{ }^{+}+89 \mathrm{H}^{+}+$ $\left.55 \mathrm{e}^{-}\right)$.

The specific energy consumption, $W_{s p}$, was calculated with the relation (4):

$$
W_{s p}=\frac{\left(Q^{*} V^{-1}\right) U}{1000}\left(\mathrm{kWhdm}^{-3}\right)
$$

where $\mathrm{Q}$ represents the specific charge consumption, $U$ is the cell voltage $(\mathrm{V}), \mathrm{V}$ is the solution volume $\left(\mathrm{dm}^{3}\right)$.

Sodium sulphate and sodium chloride solutions were analytical grade from Merck, and RR dye solutions were freshly prepared with double-distilled water.

\section{Results and discussions}

\subsection{Preliminary studies regarding electrochemical behaviour of DBR dye in aqueous solutions}

The electrochemical behaviour of the BDD electrode in $0.05 \mathrm{M} \mathrm{Na}_{2} \mathrm{SO}_{4}$ and $0.05 \mathrm{M} \mathrm{NaCl}$ supporting electrolyte in comparison with $0.1 \mathrm{M} \mathrm{Na}_{2} \mathrm{SO}_{4}$ was studied by cyclic voltammetry $(\mathrm{CV})$ to identify the electrochemical characteristics of RR dye in relation with its oxidation process on the electrode surface to set the experimental variables for degradation experiments performing. No significant differences regarding RR dye oxidation on BDD electrode in both 
supporting electrolytes were noticed (the results are not shown here). However, it is observed an important difference regarding the potential value for which a high increase of the current occurred, which can be explained by $\mathrm{O}_{2}$ evolution only in $0.1 \mathrm{M} \mathrm{Na}_{2} \mathrm{SO}_{4}$ and by chlorine and hypochlorite generation that overlapped $\mathrm{O}_{2}$ evolution in $0.05 \mathrm{M} \mathrm{Na}_{2} \mathrm{SO}_{4}$ and $0.05 \mathrm{M} \mathrm{NaCl}$ supporting electrolyte (Figure 1). The application of a large overpotential on the BDD electrode led to an indirect oxidation of dye through hydroxyl radicals $\left(\mathrm{OH}^{\cdot}\right)$ in the absence of chloride and through $\mathrm{Cl}_{2} / \mathrm{HOCl}_{\left(\mathrm{ClO}^{-}\right)}$in the presence of chloride.

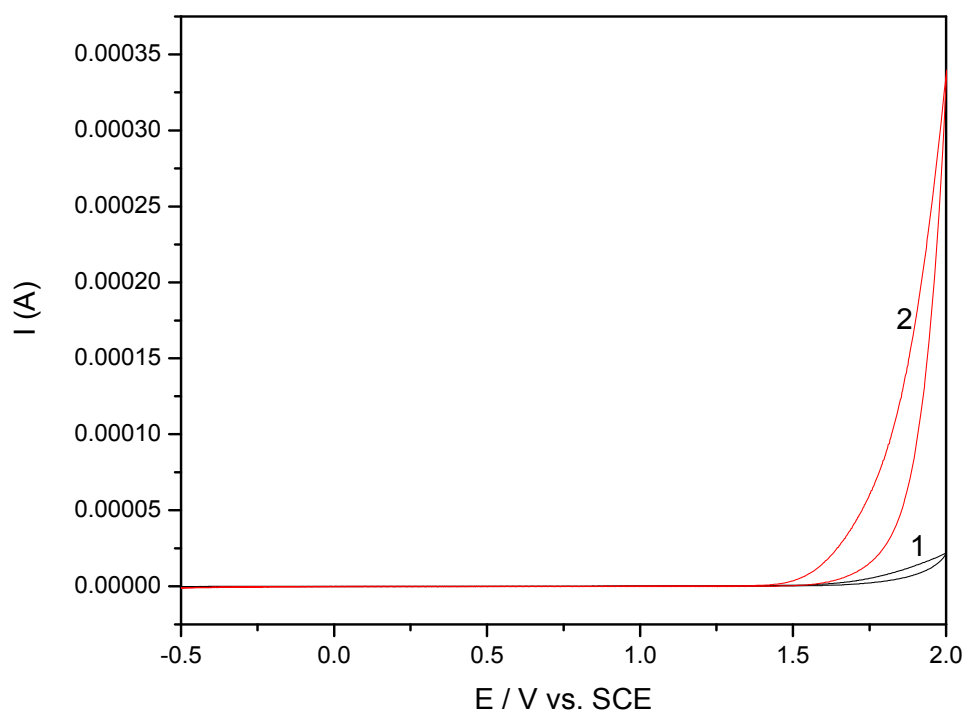

Figure 1: Cyclic voltammograms recorded at BDD electrode in: 1-0.1 M $\mathrm{Na}_{2} \mathrm{SO}_{4}$ supporting electrolyte; 2- $0.05 \mathrm{M} \mathrm{Na}_{2} \mathrm{SO}_{4}$ and $0.05 \mathrm{M} \mathrm{NaCl}$ supporting electrolyte; potential scan rate: $0.05 \mathrm{Vs}^{-1}$; potential range: -0.5 to $+1.5 \mathrm{~V} / \mathrm{SCE}$.

In order to demonstrate the generation of chlorine or hypochlorite and to identify the wavelength at which the dye concentration should be monitored by spectrophotometry during the electrooxidation process applying on $0.05 \mathrm{M}$ $\mathrm{Na}_{2} \mathrm{SO}_{4}$ and $0.05 \mathrm{M} \mathrm{NaCl}$ in the absence/presence of RR dye, UV-VIS spectra evolution was recorded (see Figure 2). It can be seen that only decolourisation can be assessed by absorbance recorded at $525 \mathrm{~nm}$ and no by absorbance recorded at $286 \mathrm{~nm}$ that corresponds to the aromatic ring opening [11] because of the hypochlorite presence at the same absorbance range. These results prove also hypochlorite generation that it is expected to oxidize the RR dye. Based on these preliminary results, the current density applied to operate the further bulk electrolysis under galvanostatic regime should belong to hypochlorite generation and water decomposition range. 


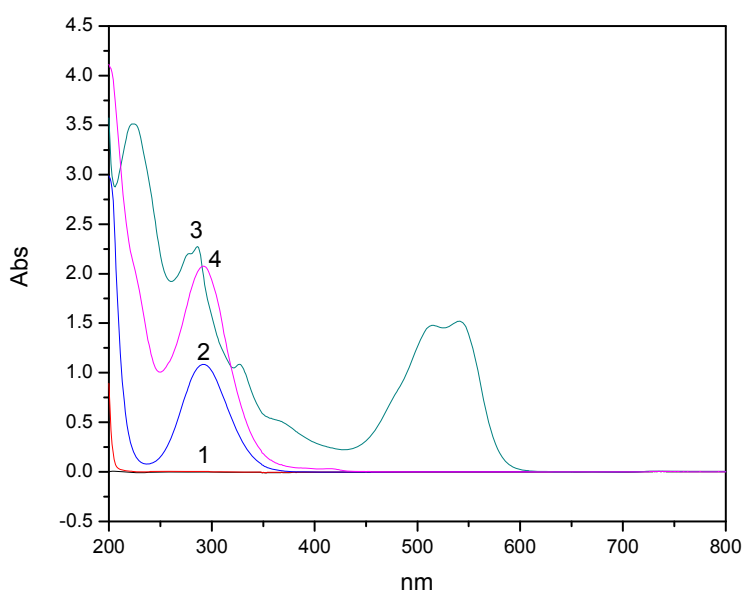

Figure 2: Evolution of UV-VIS spectra during the electrooxidation process on BDD electrode in: $1-0.05 \mathrm{M} \mathrm{Na} \mathrm{NO}_{4}$ and $0.05 \mathrm{M} \mathrm{NaCl}$ supporting electrolyte; 2- $0.05 \quad \mathrm{M} \mathrm{Na}_{2} \mathrm{SO}_{4}$ and $0.05 \mathrm{M} \mathrm{NaCl}$ supporting electrolyte after 150 min electrolysis time; $3-100 \mathrm{mgL}^{-1}$ $\mathrm{RR}$ dye in $0.05 \mathrm{M} \mathrm{Na}_{2} \mathrm{SO}_{4}$ and $0.05 \mathrm{M} \mathrm{NaCl}$ supporting electrolyte; 4- $100 \mathrm{mgL}^{-1} \mathrm{RR}$ dye in $0.05 \mathrm{M} \mathrm{Na}_{2} \mathrm{SO}_{4}$ and $0.05 \mathrm{M} \mathrm{NaCl}$ supporting electrolyte after 150 min electrolysis time; $\mathrm{pH} 5$.

The anodic oxidation of $\mathrm{RR}$ dye on $\mathrm{BDD} / \mathrm{Nb}$ electrodes in $0.05 \mathrm{M} \mathrm{Na}_{2} \mathrm{SO}_{4}$ and $0.05 \mathrm{M} \mathrm{NaCl}$ supporting electrolyte has been performed under galvanostatic regime and bulk electrolysis conditions, at two different current densities. The current densities of 10 and $30 \mathrm{~mA} \mathrm{~cm}^{-2}$ were selected to assure the conditions for the formation of hydroxyl radicals and also chlorine/hypochlorite generation at the BDD surface. The influence of operating variables, e.g., the current density, and the initial $\mathrm{pH}$ on the electrochemical process efficiency was studied to optimize them for real applications.

\subsection{Influence of current density}

Two current densities of $10 \mathrm{~mA} \mathrm{~cm}$ and $30 \mathrm{~mA} \mathrm{~cm}$ were applied for degradation of $100 \mathrm{mg} \mathrm{L}^{-1} \mathrm{RR}$ dye in $0.05 \mathrm{M} \mathrm{Na}_{2} \mathrm{SO}_{4}$ and $0.05 \mathrm{M} \mathrm{NaCl}$ supporting electrolyte at $\mathrm{pH}$ 5. In each series, the RR dye degradation efficiency was monitored in terms of decolourisation and TOC parameters. Under both current density conditions applied for the electrooxidation process, the degradation of RR dye occurred under the action of hydroxyl radicals, $\mathrm{S}_{2} \mathrm{O}_{8}{ }^{2-}$, $\mathrm{H}_{2} \mathrm{O}_{2}$ and $\mathrm{O}_{3}$ near the BDD surface or in bulk solution. Also, in chloride media, chlorine and hypochlorite are generated in-situ and used immediately. Among the strong oxidants, generation of hypochlorite is cheaper taking into account that its generation occurred at the lower overvoltage (see voltammograms presented in Figure 1) and most of the real effluents contain a certain amount of chloride. 
The decolourisation degree was slightly influenced by the current density. When current density of $30 \mathrm{~mA} \mathrm{~cm}$ was applied, the decolourisation efficiency of $100 \%$ was reached after 5 minutes of the electrolysis time, while for current density of $10 \mathrm{~mA} \mathrm{~cm}{ }^{-2}$ the complete decolourisation occurred after 6 minutes (see Figure 3). However, an important influence of the current density was manifested for the mineralization degree. It can be seen that after 10 minutes of the electrolysis time the dye mineralization degree reached $20 \%$ for the current density of $10 \mathrm{~mA} \mathrm{~cm}^{-2}$ and $48 \%$ for current efficiency $30 \mathrm{~mA} \mathrm{~cm}^{-2}$.

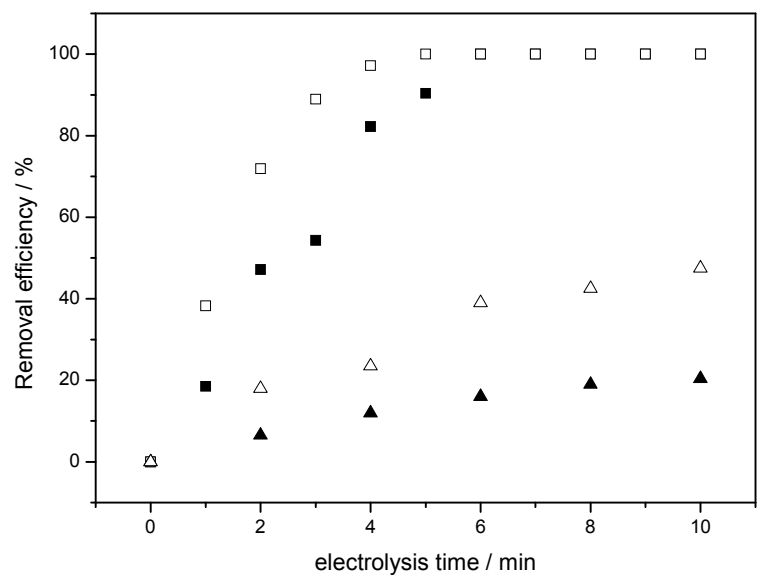

Figure 3: Evolution of dye removal efficiency versus electrolysis time; operating conditions: $0.05 \mathrm{M} \mathrm{Na}_{2} \mathrm{SO}_{4}$ and $0.05 \mathrm{M} \mathrm{NaCl}$ supporting electrolyte, $100 \mathrm{mg} \mathrm{L} \mathrm{L}^{-1} \mathrm{RR}, \mathrm{pH}$ 5. Removal efficiency: decolourisation ( $\mathbf{\square}) \mathrm{j}=10 \mathrm{~mA} \mathrm{~cm} \mathrm{~m}^{-2},(\square) \mathrm{j}=30 \mathrm{~mA} \mathrm{~cm}^{-2}$; TOC removal $(\boldsymbol{\Delta}) \mathrm{j}=10 \mathrm{~mA} \mathrm{~cm}^{-2},(\Delta) \mathrm{j}=30 \mathrm{~mA} \mathrm{~cm}^{-2}$.

The assessment of the electrooxidation performance for $R R$ dye decolourisation and mineralization was performed based on the electrochemical efficiency determination, which takes into account the charge consumed during the electrooxidation process and also, by mineralization current efficiency (Figure 4). No important influence of the current density was noticed for the electrochemical efficiency of the mineralization process and also, for the mineralization current efficiency but a great importance was found for the electrochemical efficiency of decolourisation process, which proposes to select as optimum the current density of $10 \mathrm{~mA} \mathrm{~cm}^{-2}$. The relationship between specific energy consumption and electrolysis time for each current density is shown in Figure 5, and as we expected a larger increase of the specific energy consumption at current density of $30 \mathrm{~mA} \mathrm{~cm}{ }^{-2}$ was found, which impose a limitation from the economical considerations. Based on these above-presented results, the current density value of $10 \mathrm{~mA} \mathrm{~cm}{ }^{-2}$ is considered as optimum from technical-economical point of view for both decolourisation and the degradation of RR dye from water in the presence of chloride. 


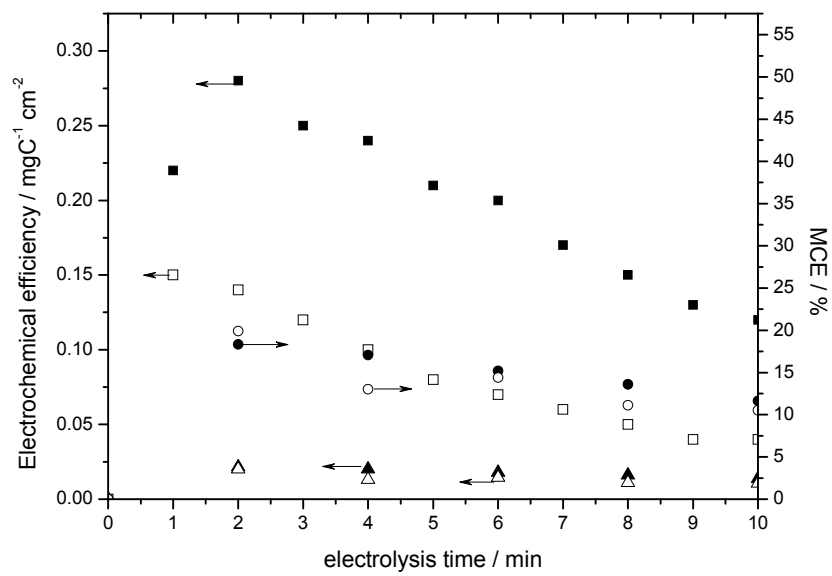

Figure 4: Correlation between electrochemical efficiency, mineralization current efficiency and electrolysis time; operating conditions: $100 \mathrm{mgL}^{-1} \mathrm{RR}, \mathrm{pH} \quad 5, \quad 0.05 \mathrm{M} \quad \mathrm{Na}_{2} \mathrm{SO} 4$ and $0.05 \mathrm{M} \mathrm{NaCl}$ supporting electrolyte.Electrochemical efficiency: decolourisation (घ) $\mathrm{j}=10 \mathrm{~mA} \mathrm{~cm}{ }^{-2},(\square) \mathrm{j}=30 \mathrm{~mA} \mathrm{~cm}^{-2}$; TOC removal $(\boldsymbol{\Delta}) \mathrm{j}=10 \mathrm{~mA}$ $\mathrm{cm}^{-2},(\Delta) \mathrm{j}=30 \mathrm{~mA} \mathrm{~cm}{ }^{-2}$. Mineralization current efficiency: $(\bullet) \mathrm{j}=10$ $\mathrm{mA} \mathrm{cm}{ }^{-2},(\circ) \mathrm{j}=30 \mathrm{~mA} \mathrm{~cm}^{-2}$.

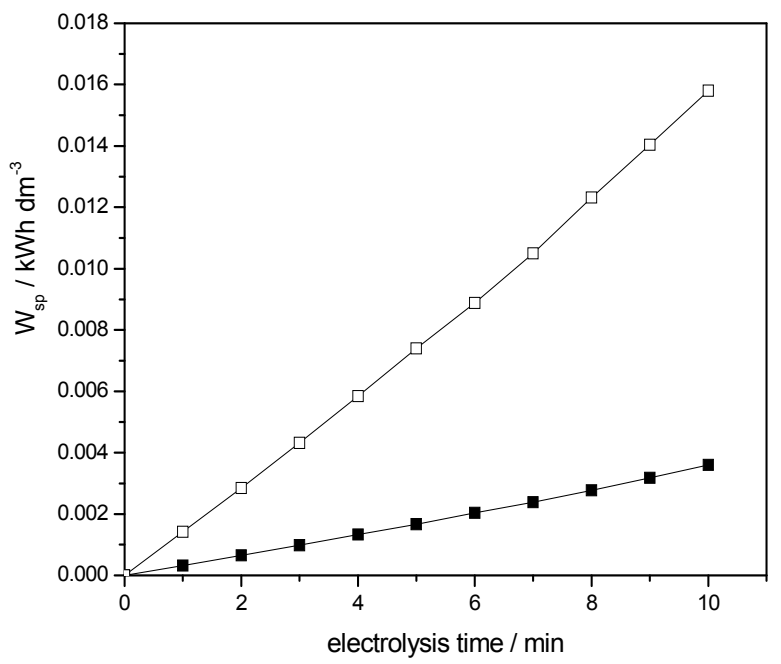

Figure 5: Evolution of specific energy consumption versus electrolysis time; operating conditions: $0.05 \mathrm{M} \mathrm{Na}_{2} \mathrm{SO}_{4}$ and $0.05 \mathrm{M} \mathrm{NaCl}$ supporting

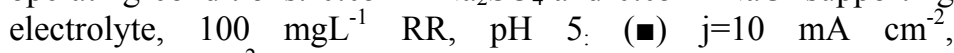
(口) $\mathrm{j}=30 \mathrm{~mA} \mathrm{~cm}^{-2}$. 


\section{3 pH influence}

The initial $\mathrm{pH}$ is on ${ }^{\mathrm{e}} \mathrm{f}$ the most important parameter ${ }^{\mathrm{i}} \mathrm{n}$ the electrolysis process. The electroxidation performance was assessed at initial $\mathrm{pH}$ of 3,5 and 9 before electrolysis, under an applied current density of $10 \mathrm{~mA} \mathrm{~cm}^{-2}$ for $100 \mathrm{mg} \mathrm{L}^{-1} \mathrm{RR}$ dye initial concentration. The results related to the dye decolourisation and mineralization efficiencies are shown in Figure 6.

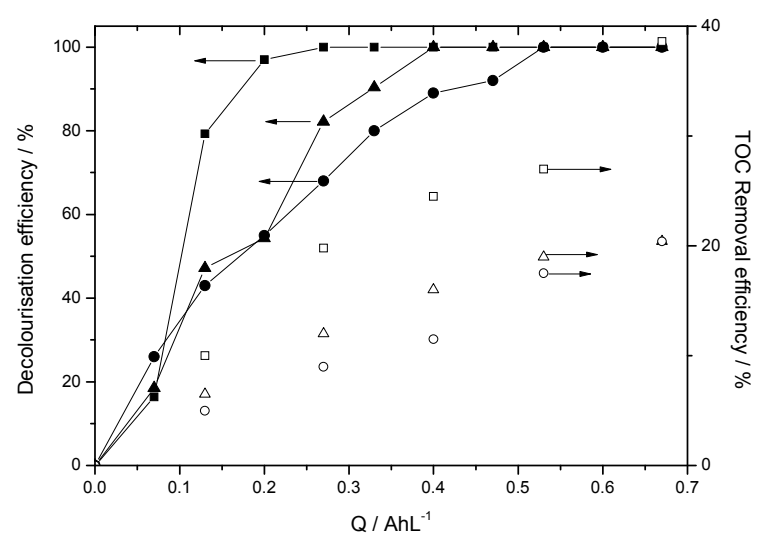

Figure 6: Correlation between decolourisation efficiency, TOC removal efficiency and charge consumption; operating conditions: $100 \mathrm{mgL}^{-1} \mathrm{RR} ; 0.05 \mathrm{M} \mathrm{Na} \mathrm{SO}_{4}$ and $0.05 \mathrm{M} \mathrm{NaCl}$ supporting electrolyte; $\mathrm{j}=10 \mathrm{~mA} \mathrm{~cm}^{-1}$; Removal efficiency: decolourisation ( $\left.\mathbf{\square}\right)$

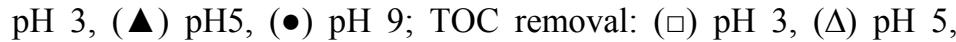
(०) $\mathrm{pH} 9$.

The performance of the dye removal process by electrooxidation was improved under more acidic versus alkaline conditions for more evidenced for mineralization in comparison with decolourisation. The influence of the $\mathrm{pH}$ mainly acts on the level of the oxidation mechanism via the action of hydroxyl radicals and chlorine/hypochlorite oxidants generated in-situ on BDD electrode surface. A possible explanation of the better results under acidic medium should be the predominant presence of hypochlorous acid that is a more effective oxidant in comparison with hypochlorite ions. In addition, acidic conditions favoured the protonation of the azo and amino groups resulting in the formation of the cationic form of RR dye that is less stable and more easily oxidisable [12].

\section{Conclusions}

The assessment of the performances of BDD electrodes in Reactive Red 147 dye electrooxidation process was accomplished based on the dye removal and electrochemical efficiencies, mineralization current efficiency and energy consumption. The dye removal and electrochemical efficiencies were assessed 
by monitoring decolourisation and mineralization degrees. The electrochemical behavior of BDD electrode in the presence of RR dye in chloride medium studied by cyclic voltammetry indicated the chlorine/hypochlorite occurring before hydroxyl radicals generation. The presence of hypochlorite was also proved by UV-VIS spectra evolution. This study demonstrated good performance of BDD electrode to degrade and mineralize RR dye from aqueous solution by indirect oxidation. No significant influence of the current density was noticed for the electrochemical efficiency of the mineralization process and also, for the mineralization current efficiency but a great influence was found for the electrochemical efficiency of decolourisation process, the current density of $10 \mathrm{~mA} \mathrm{~cm}$-2 being proposed as optimum. Also, this current density value was supported by the specific energy consumption that is in direct relation with the current density for the same electrolysis time. An improvement of the electrooxidation performance using BDD electrode was reached at acidic $\mathrm{pH}$ in comparison with alkaline media. Under the studied conditions in the presence of chloride medium, the best performance of BDD electrode for RR mineralization taking into account the technical-economical aspect was achieved at $10 \mathrm{~mA} \mathrm{~cm}$ under acidic conditions.

\section{Acknowledgements}

This work was partially supported by the strategic grants POSDRU/88/1.5/S/50783, Project ID 50783 and POSDRU/89/1.5/S/57649, Project ID 57649 (PERFORM-ERA), POSDRU/21/1.5/G/13798, co-financed by the European Social Fund - Investing in People, within the Sectoral Operational Programme Human Resources Development 2007-2013 and partially by the PNII-ID-PCE 165/2011 and PNII-RU-PD129/2010 Grants.

\section{References}

[1] Malpass, G.R.P., Miwa, D.W., Mortari, D.A., Machado, S.A.S. and Motheo, A.J., Decolorisation of real textile waste using electrochemical techniques: Effect of the chloride concentration. Water research, 41, pp. 2969-2977, 2007.

[2] Martinez-Huitle, C.A. and Brillas, E., Decontamination of wastewaters containing synthetic organic dyes by electrochemical methods: A general review. Applied Catalysis B: Environmental, 87, pp. 105-145, 2009.

[3] Riera-Torres, M. and Gutierrez, M.-C., Colour removal of three reactive dyes electrochemical treatment. Chemical Engineering Journal, 156, pp. 114-120, 2010.

[4] Gupta, V.K. and Suhas, Application of low-cost adsorbents for dye removal - A review. Journal of Environmental Management, 90, pp. 2313-2342, 2009.

[5] Kodam, K.M. and Gawai, K.R., Decolorisation of reactive red 11 and 152 azo dyes under aerobic conditions. Indian Journal of Biotechnology, 5, pp. 422-424, 2006. 
[6] Orozco, S., Bandala, E.R., Arancibia, C., Serrano, B., Suarez, R. and Hernandez, I., Effect of iron salt on the color removal of water containing the azo reactive blue 69 using photo-assisted $\mathrm{Fe}(\mathrm{II}) / \mathrm{H}_{2} \mathrm{O}_{2}$ and $\mathrm{Fe}(\mathrm{III}) / \mathrm{H}_{2} \mathrm{O}_{2}$ systems. Journal of Photochemistry and Photobiology A: Chemistry, 198, pp. 144-149, 2008.

[7] Shen, Z.M., Wu, D., Yang, J., Yuan, T., Wang, W.H. and Jia, J.P., Methods to improve electrochemical treatment effect of dye wastewater. Journal of Hazardous Materials B, 131, pp. 90-97, 2006.

[8] Panizza, M. and Cerisola G., Application of diamond electrodes to electrochemical processes. Electrochimica Acta, 51, pp. 191-199, 2005.

[9] Savas Koparal, A., Yavuz, Y., Gurel, C. and Bakır Ogutveren U., Electrochemical degradation and toxicity reduction of C.I. Basic Red 29 solution and textile wastewater by using diamond anode. Journal of Hazardous Materials, 145, pp. 100-108, 2007.

[10] Faouzi, A.M., Nasr, B. and Abdellatif, G., .Electrochemical degradation of anthraquinone dye Alizarin Red S by anodic oxidation on boron-doped diamond. Dyes and Pigments, 73, pp. 86-89, 2007.

[11] Motoc, S., Manea F., Pop A., Baciu A., Burtica G. and Pode, R., Electrochemical mineralization of Reactive Red 147 dye on boron-doped diamond electrodes. Accepted for publication in Environmental Engineering and Management Journal.

[12] Montanaro D. and Petrucci E., Electrochemical treatment of Remazol Brilliant Blue on a boron-doped diamond electrode. Chemical Engineering Journal, 153, pp. 138-144, 2009. 